\title{
HIPOCRESÍA Y SUPERSTICIÓN EN EL TEATRO CASTELLANO PRIMITIVO
}

\author{
JESỨS MAIRE BOBES
}

Una de las funciones desempeñadas por el pastor en el teatro castellano de la época de los Reyes Católicos es la de ejercer de individuo piadoso y ejemplar. No obstante, sus quejas de la injusticia reinante y sus deseos de abandonar este mundo malvado para retirarse y llevar una vida contemplativa y virtuosa no se correspondían con la realidad. Tal actitud respondía más a la simulación que a la sinceridad. El pueblo menudo ni se había caracterizado por conducirse evangélicamente en los conflictos habidos a finales del siglo XV ni en los del siglo XVI.

La rivalidad entre el judaísmo, el Islam y el cristianismo venía de largo. La Iglesia cristiana veía con malos ojos a las otras dos, pero consideraba a la Sinagoga como su competidor más peligroso. Una fórmula eficiente para desacreditarla -e incluso exterminarlaconsistía en achacarle las desventuras cotidianas, imputarle las calamidades naturales que destruían las cosechas y responsabilizarla de las pestes que arrasaban ciudades y pueblos. Los judíos - primeroy los conversos del judaísmo - después - serán los rivales contra quienes el pueblo común, azuzado por la Iglesia católica, lanzará su cólera.

Responsabilizar al odiado enemigo de las dificultades sufridas por el común de la población no resultaba difícil. ¿No eran los judíos los implacables recaudadores de impuestos? ¿No se enriquecían a costa de los préstamos usurarios y del monopolio de las rentas reales?

En épocas de crisis económica y social se exacerbaba el antijudaísmo. Las diferencias religiosas servían de pretexto para atacar a una minoría a la que se le hacía responsable de los problemas que agobiaban a las masas cristianas '. En 1378 el arcediano de Écija,

${ }^{1} \mathrm{~J}$. VALdeón, Los conflictos sociales en el reino de Castilla en los siglos XIV y XV, Madrid 1975, pág. 35. 
Ferrán Martínez, exige que las veintitrés sinagogas existentes en la ciudad sean demolidas y que se encierre en su barrio a la comunidad hebrea para que no tenga contacto con los cristianos. En 1390, habiendo fallecido el arzobispo, comienza él mismo a administrar la diócesis y ordena a sus feligreses que echen abajo todas las sinagogas de su territorio. Insinuaba que los reyes no castigarían a los atacantes. Los judíos apelaron, pero las órdenes regias no sirvieron de nada ${ }^{2}$. Las palabras del dominico Vicente Ferrer inflamaron aún más el fanatismo de los cristianos y el odio a los hebreos ${ }^{3}$. La alta clerecía castellana no permanecía al margen de estas prédicas ${ }^{4}$. Desde Sevilla la tormenta se propagó por Andalucía y Castilla. Muchos judíos se vieron abocados a la conversión forzosa. En Madrid fueron asesinados o bautizados la mayoría de ellos ${ }^{5}$. En los altercados ocurridos en Mallorca en 1391, las autoridades se vieron obligadas a suspender las deudas judiegas a los aldeanos. La demanda primordial de los campesinos era que los judíos tenían que morir o bautizarse. Los campesinos que vivían en los alrededores de Gerona fueron los responsables del incendio y saqueo de la judería. Los aldeanos de los alrededores de Teruel ponían sus ojos en el asesinato de sus aborrecidos rivales ${ }^{6}$. En las matanzas ocurridas en Córdoba en 1473 participaron activamente los campesinos de las zonas próximas a la ciudad ?

A los judíos se les impedía ejercer determinadas actividades, pero aquellos que se convertían al cristianismo tenían abiertas las puertas de los cargos más apetitosos. Las antiguas víctimas pasaban a ser los verdugos. El recelo popular poco necesitaba ya para desembocar en violentas disputas. La furia contra los conversos va a desatarse en muchas ciudades. La sublevación ocurrida en la ciudad de Toledo en 1449 será el inicio de una serie de rebeliones contra los cristianos de origen judío ${ }^{8}$ y muestra el odio de las

\footnotetext{
${ }^{2}$ Y. BAER, Historia de los judíos en la España cristiana, Madrid 1981, pág. 383.

${ }^{3}$ Ibid., pág. 439.

${ }^{4}$ Ibid., pág. 386

${ }^{5}$ Ibid, pág. 384

${ }^{6}$ Ibid., pág. 389 y ss.

7 J. VALDEÓN, Op. cit., págs. 181-182.

${ }^{8}$ A. A. Sicroff, Los estatutos de limpieza de sangre. Controversias entre los siglos XV y XVII, Madrid 1985, pág. 51.
} 
masas populares a los cristianos nuevos 9 . El barrio de la Magdalena, donde vivían los conversos más ricos de Toledo, fue saqueado. El alcalde, Pedro Sarmiento, y su ayudante, Marcos García de Mazarambrós, se apoderaron de los bienes de los mercaderes conversos ${ }^{10}$. Se proclamó un estatuto de limpieza de sangre cuyo objetivo era el de impedir que los cristianos nuevos ocuparan cargos y oficios importantes en Toledo y su concejo ". De las masas populares surgirán individuos que procurarán satisfacer sus ambiciones personales ${ }^{12}$.

Con la expulsión de 1492 no se arreglaron los problemas. A los conversos se les exigía un estricto cumplimiento del dogma. La más mínima sospecha sobre su fe podía llevarlos ante el tribunal del Santo Oficio de la Inquisición y acarrear la destrucción de más de una familia ${ }^{13}$. Como los conversos falsos, los marranos, mantenían sus costumbres judiegas ${ }^{14}$, la vida de los conversos sinceros se veía amenazada. Aunque procurasen observar el dogma escrupulosamente,

${ }^{9}$ La sentencia-estatuto de exclusión efectuada en Toledo en 1449 ejemplifica la aversión de las masas populares a los conversos. Véase E. BENITO RuANO, «Del problema judío al problema converso", en AA. VV., Simposio Toledo Judaico, Toledo 1973, vol. 2, 7-28, 16 .

${ }^{10}$ Marcos era de origen muy plebeyo. Cf. A. A. Sicroff, Op. cit., pág. 53.

11 Ibid., págs. 53-55. Cf. A. DOMÍNGUEZ ORTIZ, La clase social de los conversos en Castilla en la Edad Moderna, Granada 1991, pág. 15. Los conversos toledanos fueron inhabilitados para cargos de alcalde, alguacil, regidor, jurado y escribano, entre otros. Véase E. Benito Ruano, «La 'sentencia-estatuto' de Pero Sarmiento contra los conversos toledanos», Revista de la Universidad de Madrid VI (1957) 277-306.

12 Los estatutos del colegio de San Bartolomé de Salamanca, las cofradías de Jaén, etc., revelan una mentalidad decididamente hostil contra el converso. La saña contra las comunidades hebreas continuaría en otros lugares: Ciudad Real, Córdoba, etc. Cf. A. Domínguez Ortiz, Op. cit., págs. 13-15.

13 Se calcula que, de las doce mil personas condenadas a muerte en los tres siglos de existencia de la Inquisición española, el ochenta por ciento fueron ejecutadas durante el reinado de los Reyes Católicos. Cf. A. Domínguez Ortiz, El Antiguo Régimen: los Reyes Católicos y los Austrias, en M. ArTola (dir.), Historia de España, Madrid 1988, vol. 3, pág. 35.

14 Exteriormente vivían como cristianos. Acudian al confesionario o bautizaban a sus hijos, pero en secreto lavaban los restos de la ceremonia. No creían en los dogmas de la Iglesia, observaban el Šabbat (en aquel día podian verse muchas chimeneas sin humo) y los más puntillosos comían la carne al más puro estilo judío, suministrada por un carnicero judío. Algunos circuncidaban a sus hijos y, en la mayor parte de los casos, sólo se casaban entre ellos. Eran judios en todo excepto en el nombre y transmitian su incredulidad a sus hijos. Véase C. RoTH, Los judíos secretos. Historia de los marranos, Madrid 1979, págs. 26-27. 
estaban expuestos a sufrir las más duras penalidades si cometían el menor desliz contra la ortodoxia ${ }^{15}$.

El pueblo cristiano viejo, contando con la colaboración de la Iglesia católica, aplaudía con entusiasmo los autos de fe donde eran quemados miles de cristianos nuevos. Sin embargo, aunque la maldad anidaba en su corazón, el cristiano viejo presumía de virtuoso.

En Nave de seguridad, de Urrea, hallamos a uno de los personajes que evidencia la hipocresía del pastor. Mingo protesta porque el rebaño (los cristianos nuevos) era perseguido por los lobos (los cristianos viejos) ${ }^{16}$ :

Verás los ganados, muy grandes rabaños

los lobos y perros venir contra ellos.

Censura los males existentes en el mundo (Cancionero, fol. XCIIIv.):

Verás la justicia andar por favor,

la fuerça como agua lo lieva consigo;

no guarda amistad ya ningún amigo:

verdad ni justicia no tienen valor ...

Verás assí mismo con las presunciones

ir las virtudes caídas en suelo;

verás olvidar las cosas del cielo

y sin devoción hazer oraciones.

Despreciando el mundo de esta manera, decide cambiar su vida pastoril por la religiosa (Cancionero, fol. XCIIIv.):

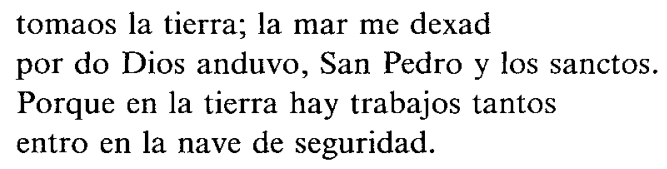

${ }^{15}$ Según el vulgo, los conversos judaizaban; ahora bien, el pueblo tomaba como indicio de judaísmo lo que en muchas ocasiones no era sino un vestigio de una cultura imposible de borrar de la noche a la mañana: no comer carne de cerdo, cambiarse de camisa los sábados, etc. Muchos de los conversos del judaísmo no tenían claros los principios del cristianismo, dudaban entre la antigua y la nueva fe; algunos se mostraban escépticos. Véase A. Domínguez OrTiz, El Antiguo Régimen, pág. 33.

${ }^{16}$ P. M. XIMÉneZ DE URREA, Cancionero de todas las obras de don Pedro Manuel de Urrea, nuevamente añadido, Toledo 1516, fol. XCIIIv. Desde ahora citaremos: Cancionero. 
Nos hallamos, por tanto, ante un pastor que posee inquietudes éticas, algo que en la realidad no se le suponía (Mingo es un despropósito cómico). Su decisión de entrar en religión refleja el singular acuerdo que existía entre el cristiano viejo y la Iglesia católica. Se oculta también en su discurso una crítica social. No obstante, en el monólogo creado por Urrea destaca, por encima de todo, una reprobación de la hipocresía del pueblo cristiano viejo. Si los cristianos viejos habían participado activamente en las persecuciones de judíos o de conversos, denunciaban a sus hermanos de fe o disfrutaban contemplando los autos inquisitoriales, ¿cómo entender este espíritu moralizador sino como expresión de la más pura hipocresía? Quien menos podía presumir de virtuoso exhibe, no obstante, un espíritu evangélico y solidario.

La Égloga de las grandes lluvias, de Encina, se refiere a los temporales que azotaron la península a fines del siglo XV. Ahora bien, sucesos como la expulsión de los judíos eran coetáneos. A la luz de acontecimientos tan dramáticos, la pieza cobra una interpretación diferente: al recordar los pedriscos, nublados o ventiscos padecidos por la población, no sólo alude Encina a las calamidades naturales que asolaron en aquellas fechas la superficie castellana, sino también a las persecuciones y expulsiones sufridas por tantos y tantos miles de personas ${ }^{17}$; la lluvia que cae del cielo adopta un significado especial; el cielo no es fuente de fertilidad, sino de excrementos y desgracias ${ }^{18}$ :

$$
\begin{array}{ll}
\text { Juan: } & \begin{array}{l}
\text { Ogaño Dios a destajo } \\
\text { tiene tomado el llover. }
\end{array} \\
\text { Rodrigacho: } & \text { A mi ver, } \\
& \text { correncia tienen los cielos. }
\end{array}
$$

El cristiano viejo no padece las alteraciones que sufren los cristianos nuevos, se halla a cubierto de cualquier contingencia (Teatro, págs. 113-114):

Miguellejo: A gran abrigada estáys.

Antón: ¡Para en tales temporales!

${ }^{17}$ F. Ruiz Ramón, Historia del teatro español. I. (Desde sus orígenes hasta 1900), Madrid 1971, pág. 32.

${ }_{18}$ R. Gimeno (ed.), Juan del Encina: Teatro (segunda producción dramática), Madrid 1987, págs. 115-116. En lo sucesivo: Teatro. 


\author{
Rodrigacho: Estos males \\ assí han de perpassar. \\ Ora, sus, sus assentar \\ tras aquestos barrancales. \\ Antón: Estamos bien abrigados.
}

El diálogo continúa con una serie de menciones a la hoguera. No sólo se subraya la despreocupación e impunidad en que vive el campesino, sino también su responsabilidad en sucesos como los autos de fe ${ }^{19}$. El cristiano viejo puede arrimarse a la llama y calentarse. El converso debe velar para no arder en ella, debe estar alerta (Teatro, págs. 114-115):
Juan: Dexarnos eys calecer.
Rodrigacho: Todos podemos caber a la lumbre rodeados.
Miguellejo: De ganados poco cuydado se os pega.
Antón: $\quad$ Más vale estar, Dios te prega, al fuego carrapuchados.
Rodrigacho: Cuydo que con más cuydado
deven estar nuestros amos. Pensarán ellos que estamos pastoreando el ganado. Ay, cuytado, quel mundo se pierde todo!
Antón: $\quad$ Todos estamos con llodo; no ay ninguno bien librado.

Las borrascas han causado más desolación en las ciudades. Que «las tormentas» fuesen más abundantes en la villa que en el campo se explica porque la mayoría del pueblo judío vivía en las ciudades (Teatro, pág. 116):
Rodrigacho: Di tú, que vienes de villa, ¿ovo gran tormenta allá?
Juan: $\quad$ ¡Dos mil vezes más que acá! ¡Tanto que no sé dezilla, de manzilla!

\footnotetext{
${ }^{19}$ Los aldeanos, la gente de las comarcas, solía acudir en masa a ver los autos de fe. Véase F. FITA, «La Inquisición toledana. Relación contemporánea de los autos y autillos que celebró desde el año 1485 hasta el de 1501», BRAH XI (1887) 289-322.
} 
Encina apunta a los expulsados y a las calamidades que padecieron (Teatro, págs. 117-118):

Con los andiluvios grandes ni quedan vados ni puentes; ya las gentes reclaman a boz en grito.

¡Andan como los de Egito! ... Cien mil álimas perdidas ...

Las casas todas caydas y las vidas puestas en tribulación.

En la Égloga pastoril, Juan Melenudo y Perantón dialogan sobre la huida de tanta gente de Valencia ${ }^{20}$. Parece evidente la alusión a los sufrimientos experimentados por los judíos que, de la noche a la mañana, se veían obligados a vender lo más preciado de su casa para conseguir asnos y carros, algo que, aunque fuese barato, se volvía caro ${ }^{21}$ (Pastoril, pág. 341):

Juan Melenudo: Que huyan todas las gentes, parad mientes, sin saber porque ni adonde... y otros dexan su casa, y do van con mala brasa son algunas ospedados. Que para pagar los carros, que son caros, venden manillas, collar, sin quererse remediar padres a fijos ni a hermanos.

${ }^{20}$ U. Cronan (ed.), Teatro español del siglo XVI, Madrid 1913, vol. 1, págs. 333365. A partir de ahora: Pastoril.

${ }^{21}$ «En el tiempo del edicto de los seis meses (los judíos) vendieron é malbarataron cuanto pudieron de sus haciendas, é aparejaron su viaje los chicos y los grandes ... y en todo ovieron siniestras venturas; ca ovieron los christianos sus faciendas muy muchas, é muy ricas casas y heredamientos por pocos dineros, y andaban (los judíos) rogando con ellas, y no habia quien se las comprase, é daban una casa por un asno, y una viña por un poco paño ó lienzo, porque no podian sacar oro ni plata; empero es verdad que sacaron infinito oro é plata escondidamente, y en especial muchos ducados é cruzados abollados con los dientes, que los tragaban é sacaban en los vientres». Cf. A. Bernáldez, Historia de los Reyes Católicos, Biblioteca de Autores Españoles LXX, Madrid 1953, pág. 652b. 
A tenor de la reflexión de Perantón, los pecados cometidos por el pueblo cristiano viejo explican las calamidades sufridas por el campo castellano a comienzos del siglo XVI (Pastoril, pág. 341):

$$
\begin{aligned}
& \text { Calla ya, necio pastor! } \\
& \text { di lo peor; } \\
& \text { que por los nuestros pecados } \\
& \text { estan ogaño los prados } \\
& \text { tan secados, ques dolor; } \\
& \text { y el ganado trashijado, } \\
& \text { mal tratado, } \\
& \text { porque no halla hartura; } \\
& \text { lo ouejuno, con tristura, } \\
& \text { lo vacuno, apellejado. }
\end{aligned}
$$

En el Auto pastoril castellano, de Gil Vicente, el pastor se despreocupa de los problemas que puedan sobrevenirles a otros ${ }^{22}$ :

$$
\begin{aligned}
& \text { Yo aquí estoy abrigado } \\
& \text { del tempero de Fortuna. } \\
& \text { Añublada está la luna, } \\
& \text { ¡mal pecado! } \\
& \text { Lloverá, soncas, priado ... } \\
& \text { Cantaré mil chançonetas, } \\
& \text { muy ufano, } \\
& \text { si allá llego bivo y sano. }
\end{aligned}
$$

Vicente alude, probablemente, a la política represiva y violenta ejercida en Portugal contra los conversos a fines del siglo XV y comienzos del XVI ${ }^{23}$. El pastor Gil no debe preocuparse: está fuera de peligro. Su impasibilidad no es óbice para que exhiba inquietudes religiosas (Dramáticas, pág. 9):

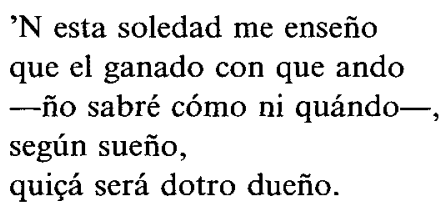

${ }^{22}$ T. R. HART (ed.), Gil Vicente: Obras dramáticas castellanas, Madrid 1975, págs. 7-8. Desde ahora: Dramáticas.

${ }^{23}$ J. A. DE Los Ríos, Historia social, política y religiosa de los judíos de España y Portugal. Tomo III: Desde Juan II hasta la dispersión, Madrid 1984, pág. 351 y ss. 
Cristo nace entre brutos animales en una época conflictiva. En la égloga segunda de Encina, Lucas se refiere a las desgracias padecidas por los judíos y a la conducta brutal de los cristianos: ${ }^{24}$

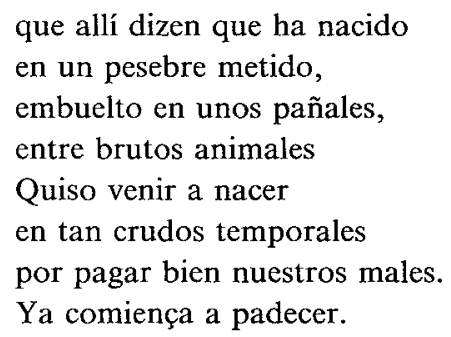

En el Diálogo del nascimiento, de Torres Naharro, Patrispano pregunta a Betiseo cómo queda España «de pan y salud». Betiseo, cuyo nombre indica que procede de una de las zonas donde la persecución de judíos y conversos fue más feroz y porfiada, se muestra insolidario con las calamidades padecidas por otros. El agradecimiento a Cristo resulta especialmente sarcástico ${ }^{25}$ :

Muy buenos, señor;

loores y gratias a aquel Redemptor, los pueblos y gentes están de tal modo que nunca la tierra se a visto mejor de sana, de harta, de fama y de todo.

La condición brutal y criminal del cristiano viejo es subrayada por las palabras empleadas por Bras en El triunfo de Amor, de Encina. Ante las explicaciones de Pelayo, quien describe los dolores que le ha causado Amor, Bras pregunta (Teatro, pág. 194):

¿Tú no le podías dar y matar?

¿Más pudo que tú un moçuelo?

\footnotetext{
${ }^{24}$ R. Gimeno (ed.), Juan del Encina: Obras dramáticas, I (Cancionero de 1496), Madrid 1975, pág. 115. A partir de ahora: Obras.

25 J. E. Gillet (ed.), Propalladia and Other Works of Bartolomé de Torres Naharro, Pennsylvania 1943, 1, pág. 270. Desde ahora: Diálogo.
} 
Mostrando su falta de ternura y de escrúpulos, se acoge a los santos para acariciar el cumplimiento de sus designios homicidas (Teatro, pág. 195):
Quisiera que le mataras
o que le despepitaras,
sí, ipara San Hedro santo!

Betiseo ha sido asaltado por unos corsarios. Guarda tal rencor a los bandidos que ruega a Dios (Diálogo, pág. 267):

que aquellos traydores los mate de sed.

El protagonista de la Égloga de Cristino y Febea, de Encina, presume de piadoso, pero en la tierra donde vive sólo hay tres hombres buenos (Teatro, pág. 232):

El hijo del messeguero

y el cuñado del herrero

y el padre de Martín Bras.

El cristiano «lindo» ${ }^{26}$ había padecido los rigores del sometimiento social, mas no había seguido las enseñanzas de Cristo (Teatro, pág. 221):

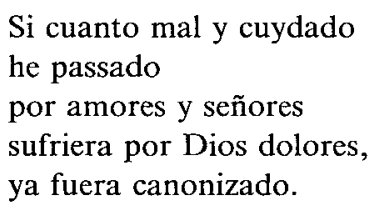

¿Es por purgar sus pecados por lo que Cristino -su nombre es elocuente- decide hacer penitencia? (Teatro, pág. 221):

Quiero buscar una hermita

benedita

do penitencia hazer

${ }^{26}$ Es el cristiano limpio. Esta palabra era utilizada en el siglo XV pero después dejó de emplearse. Procede del latín limpidus. Sobre la controversia en torno a la etimología de este vocablo, véase A. Domínguez OrTiz, La clase, pág. 13, nota 9. 


$$
\begin{aligned}
& \text { y en ella permanecer } \\
& \text { para sécula infinita. }
\end{aligned}
$$

La afirmación de Justino (Teatro, pág. 222.):

$$
\begin{aligned}
& \text { Seguir las santas pisadas } \\
& \text { y sagradas } \\
& \text { es muy bueno cuando tura; } \\
& \text { mas, cierto, cosa es muy dura } \\
& \text { dexar las cosas usadas. }
\end{aligned}
$$

insinúa que la baja condición del individuo no se cambia de la noche a la mañana. Cristino emprenderá una nueva vida, pero el recelo de su compañero, quien duda movido por justicia y razón (Teatro, pág. 224):

$$
\begin{aligned}
& \text { ¿Quién dixera que Cristino, } \\
& \text { mi vezino, } \\
& \text { viniera a ser hermitaño? } \\
& \text { No creo que cumpla el año } \\
& \text { a según que dél magino; } \\
& \text { ahotas, según quien es, } \\
& \text { que a un mes } \\
& \text { pongo en duda que él ature. } \\
& \text { Nunca más mal año dure, } \\
& \text { que amor le dará revés. }
\end{aligned}
$$

expresa bien a las claras lo difícil que resultaba que el cristiano viejo llevase una vida piadosa. Según quien es, poco tiempo persistirá en esa actitud. No pueden morar en él los sentimientos de amor o de ternura. Aunque Cristino desee llevar una vida virtuosa, sus apetitos lascivos lo traicionarán. Cuando rechace la vida religiosa y se rinda al encanto de Febea, Cristino revelará su verdadera condición. El cristiano viejo debe ocuparse de actividades viles y despreciables: correr, saltar, silbar al ganado, sorber leche u ordeñar cabras. Su religiosidad no es auténtica, vive dominado por la lujuria, no existe en él sensibilidad sino sensualidad. Justino lo expresa atinadamente (Teatro, pág. 239):

mas nunca son hermitaños

sino viejos de cien años, 


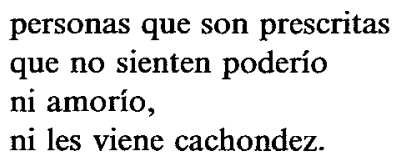

Tanta es la vanidad del villano que llegará incluso a despreciar el matrimonio con el fin de llevar una vida ejemplar. Sin embargo, la virtud no consiste tanto en dichos como en obras.

La sibila que negó sus favores a Apolo por conservar su virginidad aparece vestida de pastora en el Auto de la sibila Casandra, de Gil Vicente. Comienza sus intervenciones con estas arrogantes palabras (Dramáticas, pág. 43):

$$
\begin{aligned}
& \text { ¿Quićn mete ninguno andar } \\
& \text { ni porfiar } \\
& \text { en casamientos comigo? } \\
& \text { Pues séame Dios testigo } \\
& \text { que yo digo } \\
& \text { que no me quiero casar. } \\
& \text { ¿Quál será pastor nacido } \\
& \text { tan polido } \\
& \text { ahotas que me meresca? }
\end{aligned}
$$

Casandra presume de pureza, mas su primera réplica rebosa soberbia. Casandra encarna la doble condición de pagana (como sibila) y de cristiana (como pastora). Los errores paganos han influido de tal manera en el cristianismo que el personaje, enajenado, se niega reiteradamente a comprometerse con Salomón. La terquedad en permanecer virgen sintetiza la influencia que el paganismo ha ejercido en el cristianismo.

Salomón, que representa a la sabiduría hebrea, pretende unirse con ella, pero el cristiano lindo, imbuido de paganismo, rechazará cualquier acuerdo con el hebreo. Los judíos tienden una mano al cristiano viejo a quien ofrecen en vano sabiduría, hacienda y virtud ${ }^{27}$. A Salomón, dadas sus cualidades, le resulta difícil ofrecerse, pero busca, a pesar de todo, un entendimiento (Dramáticas, pág. 45):

\footnotetext{
${ }^{27}$ Interpretaciones diferentes a esta pueden encontrarse en L. SPITZER, «The Artistic Unity of Gil Vicente's Auto da Sibila Casandra», Hispanic Review XXVII (1959) 56-77 y en J. H. Parker, Gil Vicente, New York 1967, págs. 37-46.
} 


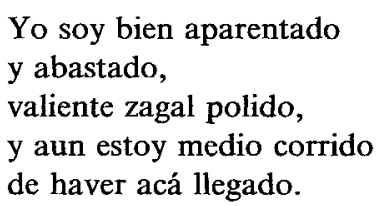

Salomón acude a Erutea, Peresica y Cimeria para que éstas intenten convencer a Casandra, pero las adivinas paganas, tías de la pastora, no disipan la obcecación. El cristiano viejo no quiere perder la pureza de su sangre (ni su libertad ni su alma) mezclándose con el hebreo. Ni a cambio de los muchos dineros de éste (Dramáticas, pág. 51):

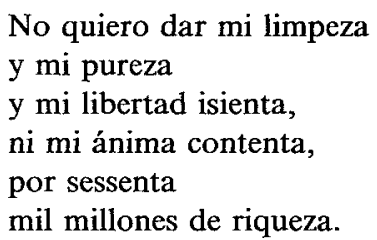

Salomón recurre a los profetas hebreos, sus tíos. Los regalos de Abrahán, de Moisés y de Isaías no socavan la decisión de Casandra. Sus propuestas de alianza a los cristianos son rechazadas sistemáticamente por éstos. Casandra explica de nuevo su determinación (Dramáticas, pág. 51):

$$
\begin{aligned}
& \text { Yo quiero ser escogida } \\
& \text { en otra vida } \\
& \text { de más perfecta manera. }
\end{aligned}
$$

La tradición pagano-cristiana admite el misterio de la encarnación. Si Casandra expone (Dramáticas, pág. 57):

$$
\begin{aligned}
& \text { sé que Dios ha de encarnar, } \\
& \text { sin dudar, } \\
& \text { y una virgen ha de parir. }
\end{aligned}
$$

Erutea, Cimeria y Peresica aceptan tamaño prodigio. No obstante, ante su quimérica pretensión de ser la elegida (Dramáticas, págs. 59$60)$ : 


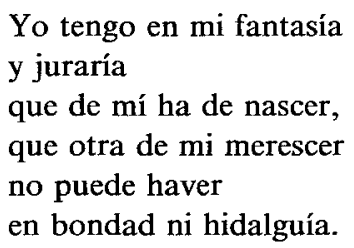

los profetas hebreos contradicen tal conjetura acusándola de orate (Dramáticas, pág. 60):

\author{
Abrahán: Ya Casandra desvaría. \\ Isaías: $\quad$ Yo dería \\ que está muy cerca de loca \\ y su cordura es muy poca, \\ pues que toca, \\ tan alta descortesía.
}

La fidelidad matrimonial de los villanos también será cuestionada. Existirán indicios de que la simulación domina en la relación familiar. En la Égloga en recuesta de unos amores, de Encina, observamos que Mingo no acompaña a su esposa, sino que requiebra a otra pastora, a Pascuala. Las preguntas de ésta (Obras, pág. 180):

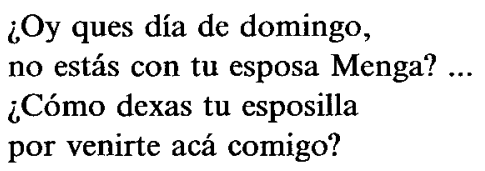

ponen en evidencia que el domingo es el día en que el matrimonio cristiano debe dar muestras de armonía. La conducta posterior de Mingo descarta que exista amor en ese matrimonio ya que no cesa de requebrar a Pascuala. Sin embargo, el cariño que Mingo guarda a la pastora no parte tanto de una emoción pura como de una pasión carnal: la belleza, la lozanía y la gallardía de la joven lo alteran. Por satisfacer sus instintos es capaz de abandonar a su mujer.

Aunque presuma de llevar una conducta ejemplar, la ausencia de fervor religioso determina la personalidad del pastor. La imposición de la Cuaresma no se vive con espíritu cristiano. En vez de prepararse de un modo austero para este período de tiempo, acorde con 
el ánimo piadoso que lo inspira, el pueblo se atraca de comida. No existe espiritualidad, sólo grosería y brutalidad. El común de la gente popular ha aceptado el precepto de la Iglesia católica en tanto en cuanto se trata de una orden, pero no ha comprendido las implicaciones espirituales que conlleva. Los pastores, en la égloga sexta de Encina, se preparan para el ayuno de Cuaresma comiendo brutalmente ${ }^{28}$ (Obras, págs. 166-168):

\begin{tabular}{|c|c|}
\hline Bras: & $\begin{array}{l}\text { Hideputa, ¡quién pudiera } \\
\text { comer más! }\end{array}$ \\
\hline Beneyto: & $\begin{array}{l}\text { Siéntate, siéntate, Bras, } \\
\text { come un bocado siquiera. }\end{array}$ \\
\hline Bras: & $\begin{array}{l}\text { No me cumpre, juro a mí. } \\
\text { Ya comí } \\
\text { tanto, que ya estoy tan ancho } \\
\text { que se me rehincha el pancho ... } \\
\text { ¿Qué tienes de comer? Di. }\end{array}$ \\
\hline Beneyto: & $\begin{array}{l}\text { Buen tocino, } \\
\text { y aqueste barril con vino } \\
\text { del mejor que nunca vi. }\end{array}$ \\
\hline Bras: & $\begin{array}{l}\text { Pues daca, daca, comamos } \\
\text { y bevamos. } \\
\text { Muera gata y muera harta ... }\end{array}$ \\
\hline Beneyto: & $\begin{array}{l}\text { Come, come, come, come, } \\
\text { no nos tome } \\
\text { la Cuaresma rellanados. }\end{array}$ \\
\hline
\end{tabular}

El villancico subraya aún más este hecho (Obras, pág. 177):
Oy comamos y bevamos y cantemos y holguemos, que mañana ayunaremos ... que todos oy nos hartemos, que mañana ayunaremos ... Comamos, bevamos tanto hasta que nos rebentemos, que mañana ayunaremos.

Esta carencia de auténtico espíritu cristiano no impedía que el pueblo viviese cómodamente instalado. El cristiano lindo, cobijado

\footnotetext{
${ }^{28}$ F. RuIz Ramón, $O p$. cit., pág. 36.
} 
en su condición de tal, vivía ajeno a cualquier contratiempo con la Inquisición ${ }^{29}$. Además, practicaba una religiosidad emparentada más con la superstición que con el ánimo piadoso y la fe auténtica. Dandario, personaje de la Comedia Aquilana, de Torres Naharro, desconoce el código amoroso cortesano y confunde los gemidos del amante desdeñado ${ }^{30}$ :

¡Ay, ay, ay, que muerto so(y)!

con las voces de un alma en pena. Para conjurarla despierta a Galterio, quien, muy contento, comienza a exorcizar (Comedias, pág. 514):

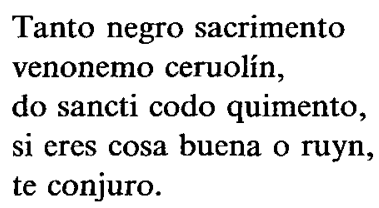

Torres Naharro ridiculiza este tipo de ceremonias, que eran realizadas y apoyadas por la autoridad eclesiástica y consideradas como necesarias por el conjunto de la sociedad ${ }^{31}$. Se utilizaban oraciones y fórmulas verbales autorizadas por la Iglesia ${ }^{32}$. El pueblo común confiaba en saludadores, ensalmadores y bendiceras. Estos vagabundos charlatanes se ganaban la vida diciendo la buenaventura, ampa-

\footnotetext{
29 ¿De qué manera contemplarían esta situación los conversos? ¿Cómo entender esta contradicción? La doctrina cristiana instruía en la virtud, en la piedad, en el amor al prójimo, en la generosidad. No obstante, las masas populares se habían distinguido en los conflictos coetáneos por practicar lo contrario. El cristiano viejo no predicaba con el ejemplo. A pesar de que su conducta no imitara los principios evangélicos y sus acciones virtuosas dejasen mucho que desear, no arriesgaba su vida porque no era sospechoso de cometer herejías. El Santo Oficio de la Inquisición no lo molestaba. Los cristianos nuevos, aunque se comportaran devotamente, se arriesgaban a la tortura, a la cárcel o a la muerte.

30 Propalladia, vol. 2, pág. 512. En lo sucesivo: Comedias.

31 A. Aponte MARín, "Conjuros y rogativas contra las plagas de langosta en Jaén (1670-1672)", en C. Álvarez - M. J. BuXó - S. Rodríguez (coords.), La religiosidad popular, Barcelona 1989, vol. 2, 554-562.

32 Para contener las hemorragias (In sanguine Adae orta est mors), para el dolor de cabeza (Virgo Maria Jordanum transivit et tunc S. Stephanus ei obviavit) o para oponerse a la mordedura de perros rabiosos (Hax, Pax, Max). Cf. H. CH. LEA, Historia de la Inquisición Española, Madrid 1983, vol. 3, pág. 576.
} 
rando las cosechas y el ganado, curando enfermedades, protegiendo contra el mal de ojo y excitando pasiones amorosas o perversas ${ }^{33}$.

E1 latín macarrónico refuerza tanto la burla como otras expresiones de Galterio quien, al mezclar bulas y sermones con lagartos y culebras, cuestiona indudablemente al cristianismo (Diálogo, págs. 514-515):

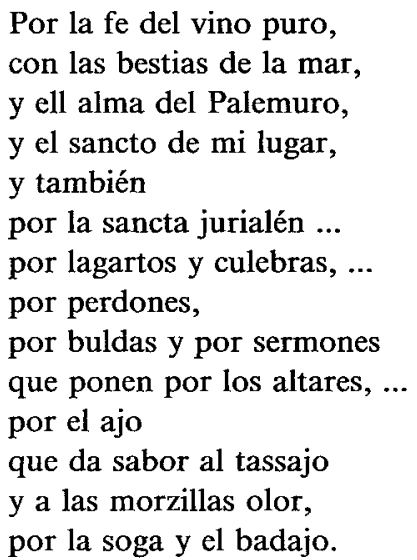

La invocación resume las prácticas mágicas de un pueblo supersticioso que admite los falsos prodigios ${ }^{34}$. Dandario y Galterio se refieren inmediatamente a Juana García, jabonera de Laredo, quien había sido quemada en Toledo por alcahueta y hechicera. Nada más ser nombrada, los hortelanos se santiguan y rezan. Ello prueba que las prácticas del cristiano viejo eran admitidas por la Iglesia y, por tanto, permitidas; las de la hechicera, en cambio, no estaban encuadradas en el esquema de la religión oficial y, por ello, eran prohibidas y castigadas ${ }^{35}$.

\footnotetext{
${ }^{33}$ bid., pág. 568.

${ }^{34} \mathrm{El}$ aldeano (paganus en latín) siempre ha permanecido aferrado a su modo de vida tradicional. Durante los siglos VI y VII la Iglesia halló en España muchas dificultades para eliminar los ritos con que los campesinos conjuraban la peste y aumentaban la fecundidad de sus ganados y la feracidad de sus campos. Cf. A. H. M. JONES, "El trasfondo social de la lucha entre el paganismo y el cristianismo", en A. Momigliano (ed.), El conflicto entre el paganismo y el cristianismo en el siglo $\mathrm{IV}$, Madrid 1989, 31-52.

35 J. L. García García, «El contexto de la religiosidad popular", en C. Álvarez - M. ${ }^{2}$ J. BUXó - S. RodRíguez (coords.), La religiosidad popular, vol. 1, 19-29.
} 
Encina se burla en su égloga quinta de la superstición del pueblo cristiano. Bras achaca al mal de ojo la congoja y aflicción que padece Beneyto (Obras, pág. 150):

$$
\begin{array}{ll}
\text { Bras: } & \text { ¿Y de qué se te achacó? } \\
\text { Beneyto: } & \begin{array}{l}
\text { No faltó } \\
\text { de cuydo, grima y cordojo }
\end{array} \\
\text { Bras: } & \text { Asmo que deve ser ojo. }
\end{array}
$$

El rústico vive en un mundo mágico y ritual. Climentejo, personaje de la Égloga pastoril, ofrece dos vacas paridas y cien cabrones a Llorente para que éste lo cure de su mal de amores. Llorente, quien no pierde de vista la posible hidalguía de la joven, lo sanará a base de encantamientos. La medicina, que a mujeres y ovejas agradará, se compone de elementos tan dispares y jocosos como la cresta de un pato bravío o el semen molido del dios Amor (Pastoril, pág. 363):

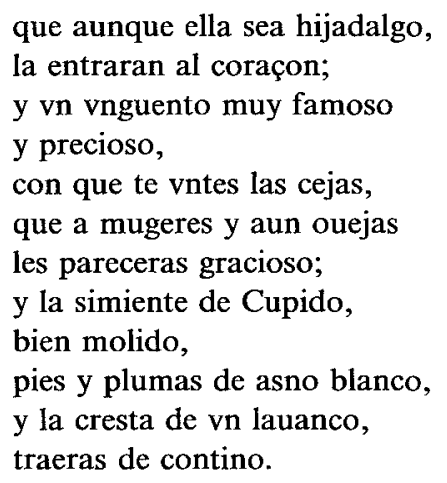

Quienes viven en la montaña son, según Braudel ${ }^{36}$, los depositarios de culturas aberrantes, basadas en hechicerías y en prácticas mágicas. El rústico concibe los símbolos religiosos -signarse- de manera supersticiosa. De ahí que antes de entrar en una estancia palaciega, asustado, acuda al santiguamiento (Obras, pág. 197):

Espera, santiguarme, porque San Jullán me dé buena estrena este verano.

${ }^{36}$ F. BRAUDEL, El Mediterráneo y el mundo mediterráneo en la época de Felipe II, Madrid 1980, vol. 1, pág. 45. 
Cree que Dios lo salvará de cualquier apuro; por ello, al entrar en la estancia donde se encuentran los duques, afirma (Obras, pág. 197):

vamos en nombre de Dios.

El cristiano lindo se nutre de unas creencias basadas en el paganismo y en una moral utilitaria; considera que, rezando a los dioses, éstos le garantizan seguridad. Lo observamos en el Auto o farsa del nascimiento de Fernández. La rudeza de Juan se advierte cuando pretende saltar desde un alto para llegar a donde están los demás pastores. Creyendo en el misterio de la Trinidad, salvoconducto para el ignorante, y haciendo la señal de la cruz, estará a salvo de todo mal ${ }^{37}$ :

$$
\begin{array}{ll}
\text { Juan: } & \text { O Jesu, prizilim cruces. } \\
& \text { ¡Nombre de Dios verdadero, } \\
& \text { trino y vno todo entero! } \\
& \text { ¿Vesme, vesme dónde vo? } \\
\text { Lloreynte: } & \text { ¡Guarda, que te harás pedaços! }
\end{array}
$$

E1 pueblo rezaba a Jesús, a la Virgen o a los santos para que éstos le resolvieran sus problemas. En el teatro se observa esta costumbre tan tradicional que aún en nuestros días es practicada por el pueblo: el vulgo estima que, aceptando a Jesús y orando, las dificultades serán más fáciles de sortear. En la égloga segúnda de Encina los pastores acogen con entusiasmo la noticia del nacimiento del Mesías. El autor se burla de la moral utilitaria del pueblo cristiano. Éste imagina que Cristo va a resolverle todos los problemas. Va a salvarlos (Obras, pág. 111):

$$
\begin{array}{ll}
\text { Juan: } & \text { Nació nuestro Salvador } \\
& \text { por librar nuestra pelleja. } \\
\text { Lucas: } & \text { ¡Qué pastor tan singular } \\
& \text { te parece este donzel! } \\
& \text { Todos bivamos con él } \\
& \text { que éste nos viene a salvar. }
\end{array}
$$

${ }^{37} \mathrm{M}^{\mathrm{a}} \mathrm{J}$. Canellada (ed.), Lucas Fernández: Farsas y églogas, Madrid 1981, pág. 197. Desde ahora: Farsas. 
Encina cuestiona la hipótesis cristiana de la salvación. No parece justo que únicamente se salven quienes toleren el yugo de Jesús (Obras, págs. 111-112):

$\begin{array}{ll}\text { Mateo: } & \text { Miafé, con él nos uñamos } \\ & \text { que su yugo es muy suave, } \\ & \text { y su carga no es muy grave } \\ & \text { mas muy leve si miramos ... } \\ \text { Lucas: } & \text { Muy humildes le seamos, } \\ & \text { que si bien nos umillamos } \\ \text { bien ensalçados seremos. }\end{array}$

Felices los cristianos, ¿que sucederá con quienes no acepten el yugo de Cristo? Esta moral utilitaria se manifiesta cuando Juan alude a la multiplicación del pan. Encina se guasea del Evangelio ${ }^{38}$, de la Eucaristía y del pueblo cristiano ${ }^{39}$. El pastor dejará de comer «vianda vil» como un perro y se cebará copiosamente. El rústico posee, pues, un concepto materialista de la fe. Juan exclama (Obras, pág. 113):

\footnotetext{
¡Hartar, hartar ya, gañanes, ques venido pan del cielo, pan de vida y de consuelo! No comáys somas de canes, ni andéys hechos albardanes comiendo vianda vil,
}

\footnotetext{
${ }^{38}$ Lucas cuenta cómo Jesús dio de comer con cinco panes y dos peces a cinco mil personas. Caía la tarde en Betsaida y los apóstoles pidieron a Jesús que despidiera al gentío pero él les ordenó que alimentaran a la muchedumbre: «Replicaron ellos: ${ }_{-i} \mathrm{Si}$ no tenemos más que cinco panes y dos peces! A menos que vayamos nosotros a comprar de comer para toda esta multitud. (Eran unos cinco mil hombres). Jesús dijo a los discípulos: -Decidles que se echen en grupos de cincuenta. Así lo hicieron, diciendo que se echaran todos. Y tomando él los cinco panes y los dos peces, alzó la mirada al cielo, los bendijo, los partió y se los dio a los discípulos para que se los sirvieran a la gente. Comieron hasta quedar satisfechos todos, y recogieron doce cestos de sobras». Cf. L. Alonso SchöKel y J. MAteos (trads.), Nueva Biblia Española, Madrid 1977, pág. 1610.

${ }^{39}$ En la liturgia el oficiante recuerda el mensaje: «el que coma de este pan vivirá para siempre». La nueva proclamada por Juan cobra un sentido mordaz: el pan del cielo (Cristo) sacia el hambre de los gañanes (el pueblo) y los consuela de sus miserias y calamidades. La hambruna y la estulticia motivan a este pueblo para creer en Cristo.
} 


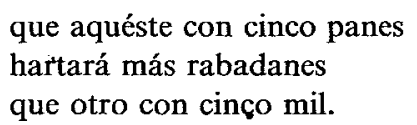

Este concepto egoísta del cristianismo también convence a Pascual ${ }^{40}$, quien antes se había mostrado reacio a reconocer a Jesús (Farsas, pág. 203):

O, Señor, tu señorança

y tu terribre alabança me quiera dar saluación, después grorificación.

y a Lloreynte (Farsas, pág. 204):

que nos viene a dar la ley para auernos de saluar.

Para desenmascarar el proceder hipócrita seguido por los cristianos viejos en el conflictivo período que media entre 1492 y 1517 , el teatro renacentista presenta a una serie de individuos que, aunque presumieran de conducirse devotamente, se comportaban de manera cruel e insolidaria con sus nuevos hermanos de fe.

Esta carencia de espiritualidad se manifestaba reiteradamente. La soberbia podía más en su ánimo que la generosidad. Los grandes acontecimientos religiosos no eran celebrados con austero fervor, sino de forma brutal y ordinaria. La superstición por ellos practicada los emparentaba más con el paganismo que con el mensaje evangélico. Eran cristianos en tanto en cuanto «sabían» que Cristo los salvaría y los guardaría de penalidades y violencias, pero no porque la ternura y la misericordia anidaran en sus corazones.

${ }^{40}$ Se ha dicho que en estas églogas de Navidad se produce la «conversión» del pastor bobo. Saliendo de una época de oscuridad y tinieblas, el pastor sería iluminado en la gracia divina y se convertiría a la ley de Cristo. Véase J. Brotherton, The "Pastor-Bobo" in the Spanish Theatre. Before the Time of Lope de Vega, London 1975, págs. 1-22. Ahora bien, es preciso tener en cuenta que tanto el egoísmo como la ignorancia presiden tal decisión. Una fe basada en una concepción religiosa tan utilitaria (Cristo los salva, les da de comer...) deja mucho que desear. Una conversión tan rápida (los catequizados son ignorantes) ha de ser necesariamente frágil y poco profunda. Además, ¿era justo que únicamente se salvasen los creyentes? ¿mostraban espíritu generoso y piadoso quienes condenaban a aquellos que no creían en Cristo? 


\section{RESUMEN}

Este artículo trata de los villanos que aparecen en el primitivo teatro castellano. Partimos de la existencia de una realidad social: aunque el pueblo presumía de su cristianismo, no se conducía virtuosamente, pues delataba a los conversos del judaísmo (a quienes odiaba) y disfrutaba contemplando los autos de fe; no era piadoso, sino hipócrita y supersticioso. En el análisis se incluyen textos de Encina, Fernández, Gil Vicente, Torres Naharro y otros autores, quienes censuraban en sus obras esta doble moral del pueblo cristiano viejo.

\section{SUMMARY}

This article deals with the character of the villagers who come in on the early Spanish theatre. The starting point is the fact, actually existing in the society of that time, that the people were proud of their Christianity but did not behave in a virtuous way: they often denounced the converts from Judaism (chief aim of their hatred) and they enjoyed the autos de fe; far from being pious, they were hypocrite and supersticious. In the analysis, texts by Encina, Fernández, Gil Vicente, Torres Naharro and others are included. These authors strongly disapproved the double morals of those people known as cristianos viejos. 